\title{
CONDUTIVIDADE HIDRÁULICA DE RAIZ E CAPACIDADE FOTOSSINTÉTICA DE MUDAS CLONAIS DE EUCALIPTO COM INDUÇÃO DE DEFORMAÇÕES RADICULARES
}

\author{
ROOT HYDRAULIC CONDUCTIVITY AND PHOTOSYNTHETIC CAPACITY OF \\ EUCALYPT CLONAL CUTTINGS WITH ROOT MALFORMATION INDUCTIONS
}

Fábio Afonso Mazzei Moura de Assis Figueiredo ${ }^{1}$ José Geraldo de Araújo Carneiro ${ }^{2}$ Ricardo Miguel Penchel ${ }^{3}$ Eliemar Campostrini ${ }^{4}$ José Tarcísio de Lima Thiebaut $^{5}$ Deborah Guerra Barroso ${ }^{6}$

\begin{abstract}
RESUMO
A redução do ganho em biomassa de lenho em árvores tem sido atribuída à ocorrência de deformações radiculares ainda na fase de viveiro. O objetivo deste trabalho foi avaliar a condutividade hidráulica do sistema radicular, trocas gasosas e a eficiência fotoquímica de mudas clonais de eucalipto com e sem indução de deformações radiculares. Os tratamentos foram: 1 - mudas sem a indução de deformações radiculares (produzidas de acordo com metodologia operacional do viveiro da Fibria Celulose S.A.) e 2 - mudas com indução de deformações radiculares. A indução da deformação radicular não resultou em queda no volume radicular. Contudo, deformações radiculares provocaram redução na condutividade hidráulica do sistema radicular, assim como foram verificadas quedas na taxa fotossintética das mudas ao longo do dia. A queda da taxa fotossintética em mudas com indução de deformações radiculares está associada a fatores estomáticos e não estomáticos.
\end{abstract}

Palavras-chave: Eucalyptus spp; condutividade hidráulica; sistema radicular; trocas gasosas.

\begin{abstract}
The gain reduction of wood biomass in trees has been assigned to root deformations even in the nursery phase. The objective of this work was the evaluation of the root system hydraulic conductivity, gas exchanges and photochemical efficiency of eucalypt clonal cuttings with and without root deformation inductions. The treatments were: 1) operational cuttings without root malformation inductions (grown according to the used methodology of Fibria Cellulose S.A.); 2) root deformation inductions. These inductions did not promote decrease in the root volume. However, the deformations brought reduction of the root system hydraulic conductivity. Lower photosynthetic rates were also observed along the day in the cuttings in the root deformed cuttings. This decreasing rate is connected to stomatal and non stomatal factors.
\end{abstract}

Keywords: Eucalyptus spp; hydraulic conductivity; root systems; gas exchange.

1 Engenheiro Agrônomo, Dr., Pós-Doutorando em Fisiologia Vegetal, Universidade Estadual do Norte Fluminense Darcy Ribeiro, CEP 28013-602, Campos dos Goytacazes (RJ), Brasil. fabio_uenf@yahoo.com.br

2 Engenheiro Florestal, Dr., Pesquisador Associado da Universidade Estadual do Norte Fluminense Darcy Ribeiro, CEP 28013-602, Campos dos Goytacazes (RJ), Brasil. carneiro@uenf.br

3 Engenheiro Agrônomo, PhD., Técnico da Empresa Fibria Celulose S/A, Rdv. Gal. Euryale de Jesus Zerbine, Km 84, Jardim São Gabriel, CEP 12340-010, Jacareí (SP), Brasil. rp@fibria.br

4 Engenheiro Agrônomo, Dr., Professor Associado da Universidade Estadual do Norte Fluminense Darcy Ribeiro, CEP 28013-602, Campos dos Goytacazes (RJ), Brasil. campostenator@gmail.com

5 Engenheiro Agrônomo, Dr., Professor Associado da Universidade Estadual do Norte Fluminense Darcy Ribeiro, CEP 28013-602, Campos dos Goytacazes (RJ), Brasil. jtt1512@oi.com.br

6 Engenheira Agrônoma, Dr., Professora Associada da Universidade Estadual do Norte Fluminense Darcy Ribeiro, CEP 28013-602, Campos dos Goytacazes (RJ), Brasil. deborah@uenf.br

Recebido para publicação em 25/04/2011 e aceito em 10/09/2012

Ci. Fl., v. 24, n. 2, abr.-jun., 2014 


\section{INTRODUÇÃO}

A função primária do sistema radicular é de adquirir a água, os macro e micronutrientes e promover a ancoragem da planta ao solo. Este sistema atua de maneira secundária no armazenamento de fotoassimilados, na síntese de fito-hormônios e na propagação clonal (OSMONT et al., 2007). Portanto, o crescimento e a produtividade da planta estão diretamente relacionados a uma ótima atividade do sistema radicular.

Quando se tem restrição mecânica do sistema radicular, a diminuição no crescimento da parte aérea de uma planta é constante, ainda que as plantas apresentem ausência de deficiência nutricional (CARMI e HEUER, 1981; RUFF et al., 1987; PETERSON et al., 1991). Tal redução no crescimento pode estar relacionada ao desbalanço fito-hormonal (TERNESI et al., 1994; HURLEY e ROWARTH, 1999) e a limitação hídrica (HAMEED et al., 1987). Essa restrição mecânica pode causar alterações na anatomia da raiz o que pode causar as intensas reduções na condutividade hidráulica deste órgão (SOLARI et al., 2006).

Contudo, segundo Reis et al. (1991), as plantas com o sistema radicular deformado apresentam menor capacidade de absorção de nutrientes, visto que os pontos de deformação podem oferecer resistência ao movimento de água, e indiretamente provocar o desbalanço nutricional, comprometendo assim a produtividade da planta. De acordo com Freitas et al. (2005), na condição de campo, as mudas com deformações radiculares no viveiro podem reduzir o crescimento, acarretando maiores custos na manutenção do povoamento florestal. Além disso, as plantas podem reduzir significativamente o incremento de biomassa. Novaes et al. (2002), Barroso et al. (2000) e Freitas (2003) verificaram que, após o plantio na condição de campo, as mudas produzidas sob restrição mecânica do sistema radicular apresentaram sérias deformações radiculares e menores taxas de crescimento inicial, o que acarretou em perdas de produtividade.

Para o crescimento da parte aérea, as plantas necessitam de um sistema radicular que forneça de forma adequada água e nutrientes (BENGOUGH et al., 2006). A aquisição da água pelo sistema radicular e o transporte desta molécula por toda a planta estabelece um fluxo (TYREE, 2003), que é originado pela demanda evaporativa da copa das árvores, constituindo um continuum hidráulico solo-planta-atmosfera (NIKOLOVA et al., 2009). Portanto, a maior condutividade hidráulica da raiz é um fator crucial no abastecimento de água para a parte aérea da planta.

De acordo com Huang e Nobel (1994), a condutividade hidráulica da raiz combina os componentes de condutividade em todo o sistema radicular, da superfície da raiz para o xilema e deste para a base do caule. De acordo com Tyree e Zimmermann (2002), as características anatômicas do sistema radicular pode apresentar um impacto sobre a condutividade hidráulica deste órgão. Huang e Eissenstat (2000) e Solari et al. (2006) relatam, também, que as diferenças de condutividade hidráulica podem ser relacionadas com a anatomia da raiz. Para Jackson et al. (2000), as variações na anatomia do xilema e as propriedades hidráulicas ocorrem em vários níveis, como interespecífica, intraespecífica e dentro da própria planta. De acordo com McElrone et al. (2004), a resistência ao fluxo de água no xilema é determinada em parte pelo diâmetro e pelo comprimento dos vasos condutores responsáveis pelo transporte desta molécula.

Um dos principais problemas em mudas de eucalipto produzidas em recipientes de $53 \mathrm{~cm}^{3}$ é a deformação do sistema radicular. Supõe-se que as deformações radiculares induzam alterações no diâmetro dos vasos do xilema, provocando uma menor condutividade hidráulica do sistema radicular, e também, com reflexos nas trocas gasosas. Sendo assim, o presente trabalho objetivou avaliar a condutividade hidráulica do sistema radicular, trocas gasosas e a eficiência fotoquímica de mudas clonais de eucalipto, com e sem a indução de deformações no sistema radicular.

\section{MATERIAL E MÉTODOS}

\section{Material vegetal e condições de cultivo}

$\mathrm{O}$ experimento foi realizado no viveiro de produção de mudas da empresa FIBRIA, em Aracruz-ES, entre os meses de julho e outubro de 2010. As avaliações foram realizadas neste ultimo mês, e foram utilizadas mudas clonais de um único clone híbrido de Eucalyptus grandis $x$ Eucalyptus urophylla, selecionado por estar sendo produzido comercialmente e apresentar alta taxa de enraizamento. As mudas foram produzidas a partir de miniestacas apicais $(8-10 \mathrm{~cm})$, de acordo com o sistema usual de produção da empresa. Neste sistema, as miniestacas foram coletadas a partir de 


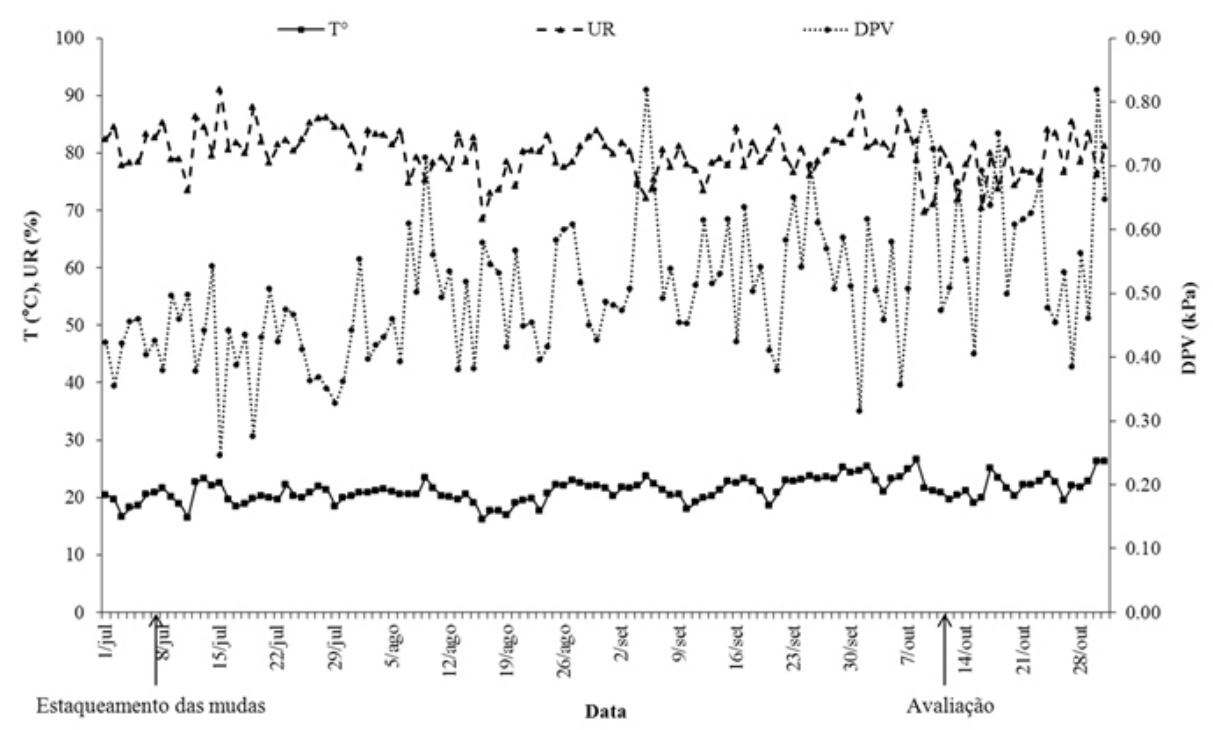

FIGURA 1: Dados médios diários de temperatura (T), umidade relativa do ar (UR) e deficit de pressão de vapor do ar (DPV).

FIGURE 1: Daily average data of temperature (T), air relative humidity (UR) and steam pressure deficit (DPV).

minicepas cultivadas em canaletões contendo areia com solução nutritiva, sob condição de casa de vegetação.

Após o estaqueamento no substrato contendo uma mistura composta por fibra de coco $(30 \%)$, casca de arroz carbonizada (35\%) e vermiculita (35\%), com o incremento de $2,0 \mathrm{~kg} \mathrm{~m}^{-3}$ de osmocote (19-6-10) e 2,0 $\mathrm{kg} \mathrm{m}^{-3}$ de superfosfato simples, as mudas permaneceram por 20 dias em casa de vegetação, com nebulização intermitente. Posteriormente, permaneceram por mais 30 dias em casa de sombra, com redução de $70 \%$ da intensidade luminosa e mais 60 dias a pleno sol, para a rustificação. Na Figura 1 são apresentados os dados médios diários de temperatura, umidade relativa e o deficit de pressão de vapor durante o período de produção das mudas.

As mudas foram produzidas em recipientes plásticos de secção circular, do tipo tubetes, com volume de $53 \mathrm{~cm}^{3}$. Para tanto, foram estabelecidos dois tratamentos, um considerado sem indução de deformações (SD) e o outro com indução de deformação do sistema radicular (CD). Para o tratamento com indução da deformação, considerouse a secção circular dos recipientes em quadrantes e foram feitos quatro cortes, um em cada quadrante (Figura 2). O primeiro corte foi feito a $2,5 \mathrm{~cm}$ da borda superior do tubete e os demais, distantes de
A

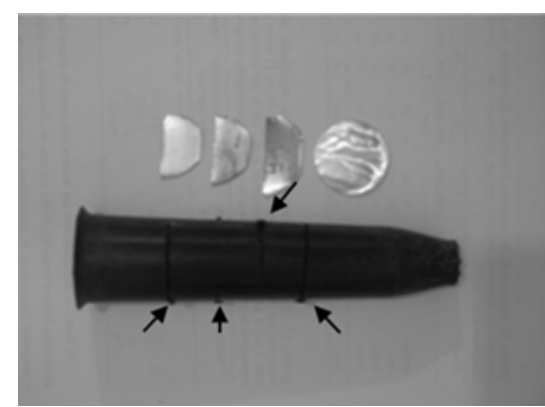

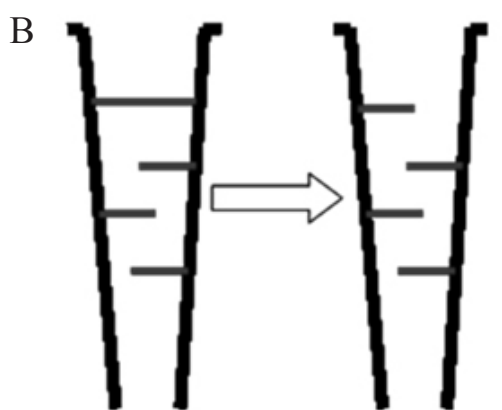

FIGURA 2: Foto das plaquetas colocadas nos tubetes para induzir as deformações radiculares e o tubete de $53 \mathrm{~cm}^{3}$ com cortes para introdução das plaquetas (A). Ilustração da distribuição das plaquetas antes e após a troca da primeira plaqueta (B).

FIGURE 2: Position of thin metal sheets as a barrier to be inserted into the tubes $\left(53 \mathrm{~cm}^{3}\right)$, to induce root malformations (A). Distribution of the sheets before and after the exchange of the first sheet (B). 
$1,5 \mathrm{~cm}$ entre si. Nestas aberturas, foram introduzidas pequenas plaquetas de alumínio que cobriam $50 \%$ do diâmetro interno do recipiente (Figura 2).

No primeiro corte feito no tubete, correspondente ao tratamento em que se induziu a deformação radicular (CD), e durante os primeiros 20 dias de cultivo, foi colocada uma plaqueta circular que cobria, praticamente, toda a secção interna do recipiente. Isto foi feito para que as raízes iniciais emitidas na estaca apresentassem uma deformação inicial logo após a sua emissão. Após este período, a plaqueta circular foi substituída por uma plaqueta, igual às demais, ou seja, cobrindo apenas $50 \%$ do diâmetro interno do recipiente.

Os quatro cortes e a presença das plaquetas de alumino foram feitos com o objetivo de que as raízes encontrassem restrição mecânica ao crescimento natural, forçando-as a contornar os obstáculos e, com isso, induzir as deformações, em forma de dobras.

No final do experimento (110 dias após o estaqueamento), a condutividade hidráulica e o volume do sistema radicular, o teor de clorofila, as trocas gasosas e a eficiência fotoquímica foram avaliados.

\section{Condutividade hidráulica da raiz $\left(K_{L}\right)$}

A avaliação de $k_{l}$ foi feita utilizando uma câmara de pressão (SoilMoisture, California, USA). Para tanto, as mudas foram seccionadas a $7 \mathrm{~cm}$ contados a partir do colo. Em seguida, o sistema radicular foi colocado em um recipiente saturado com água, e rapidamente as raízes foram postas com este recipiente saturado dentro da câmara de pressão. Cerca de $5 \mathrm{~cm}$ do caule ficou para o lado de fora da câmara. Em cada muda foram aplicadas lentamente pressões crescentes de 0,$1 ; 0,2 ; 0,3$ e $0,4 \mathrm{MPa}$, e em cada valor de pressão aplicado, o tempo utilizado foi de cinco minutos. Com o auxilio de papel absorvente, todo o conteúdo de água exsudado no corte foi coletado e pesado em uma balança analítica de precisão. Em cada tratamento, foram utilizadas 15 mudas.

\section{Volume do sistema radicular}

O volume do sistema radicular foi avaliado utilizando-se as mesmas mudas usadas na avaliação da condutividade hidráulica. Depois de lavado, o sistema radicular foi colocado em uma proveta graduada com água e o volume estimado pelo deslocamento do nível da água (ROSSIELLO et al., 1995).

\section{Trocas gasosas, eficiência fotoquímica máxima do fotossistema II (PSII) e estimativa do teor de clorofilas totais}

Nas avaliações das trocas gasosas (taxa fotossintética líquida (A), condutância estomática $\left(\mathrm{g}_{\mathrm{s}}\right)$, e transpiração $\left.(\mathrm{E})\right)$ da eficiência fotoquímica máxima do PSII e do teor de clorofilas, foram utilizadas folhas plenamente expandidas, no terceiro par contado a partir do ápice da planta. Para estas avaliações, e em cada tratamento, foram utilizadas seis plantas. Ao longo do dia, e nos horários das $9 \mathrm{~h}$ às $15 \mathrm{~h}$ horas, a cada hora foram realizadas as medições. Para esta medição das trocas gasosas, foi utilizado um sistema portátil de medição das trocas gasosas modelo LI-6400 (LI-COR, Lincoln, NE, USA) e as medidas foram feitas a uma intensidade luminosa de $1500 \mu \mathrm{mol} \mathrm{m}^{-2} \mathrm{~s}^{-1}$.

A avaliação da eficiência fotoquímica máxima do PSII foi feita nos mesmos horários e nas mesmas folhas utilizadas nas medições das trocas gasosas. Durante a avaliação, foi utilizado um fluorímetro não modulado modelo PEA (Hansatech Instruments Ltd, King's Lynn, Norfolk, UK). Para tanto, antes da medição da eficiência fotoquímica, foi feita uma adaptação ao escuro da área amostrada da folha por 30 minutos, para que todos os centros de reação adquirissem a condição de abertos (BOLHÀR-NORDENKAMPF et al., 1989). Após os 30 minutos de adaptação, foi aplicado um pulso de luz de intensidade de $3500 \mu \mathrm{mol} \mathrm{m}^{-2} \mathrm{~s}^{-1} \mathrm{e}$ em seguida foi determinado os valores de $\mathrm{F}_{0}, \mathrm{~F}_{\mathrm{v}}$ e $\mathrm{F}_{\mathrm{m}}$. A partir dos valores destas, foi possível obter o valor do rendimento quântico máximo do PSII $\left(\mathrm{F}_{v} / \mathrm{F}_{\mathrm{m}}\right)$, uma vez que $\mathrm{F}_{\mathrm{v}}=\mathrm{F}_{\mathrm{m}}-\mathrm{F}_{0}$ (BOLHÀR-NORDENKAMPF et al., 1989).

O teor de clorofila foi estimado por meio do medidor portátil de clorofilas, OPTISCIENCE, modelo - CCM 200. Durante as medidas foram utilizadas as mesmas plantas e folhas das avaliações de trocas gasosas e da eficiência fotoquímica do PSII. Em cada folha foram feitas 3 determinações, sendo a medição realizada às $10 \mathrm{~h}$.

Na Figura 3 são apresentados os dados médios de temperatura, umidade relativa e deficit de pressão de vapor do ar e radiação global e radiação fotossinteticamente ativa (PAR), durante os horários de avaliação das mudas. 

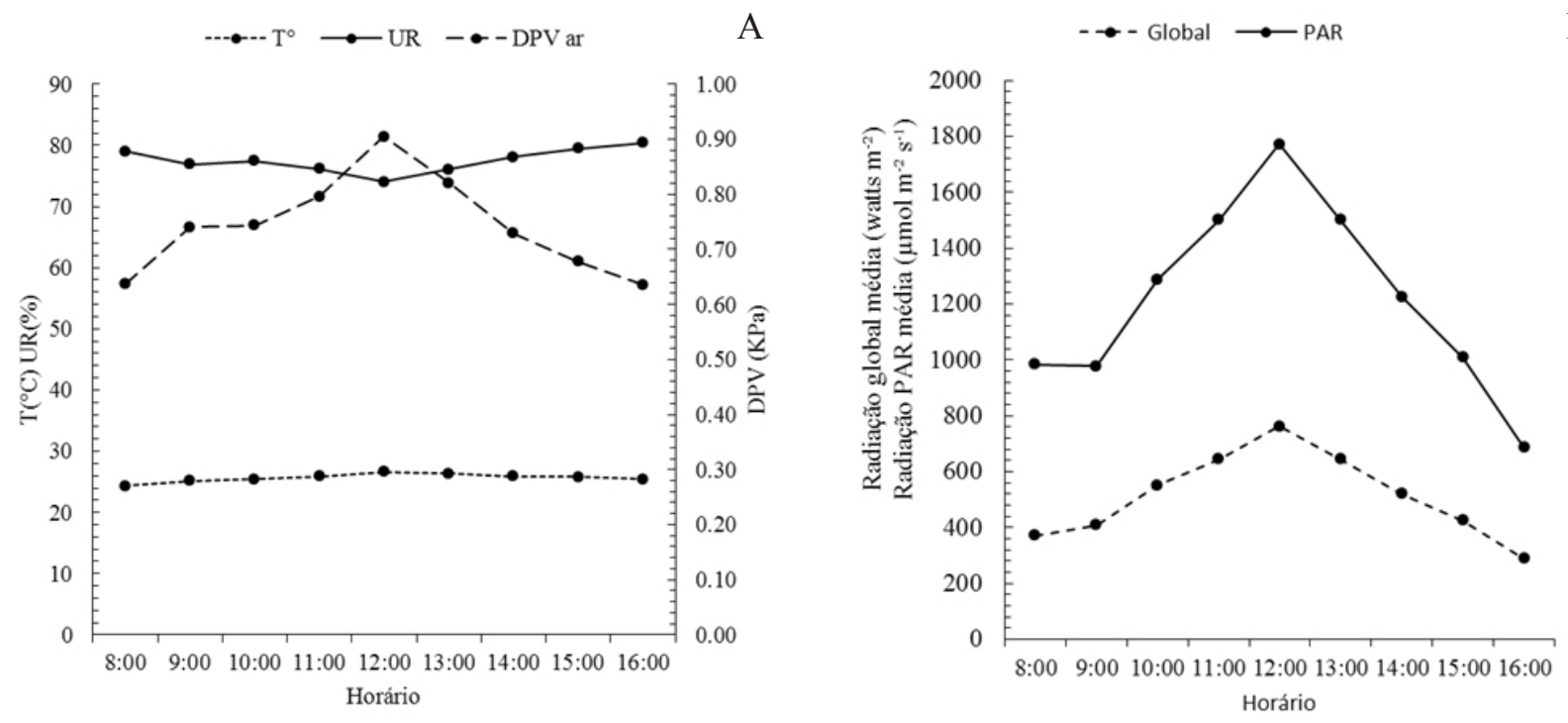

FIGURA 3: Dados médios de temperatura (T), umidade relativa (UR) e deficit de pressão de vapor do ar (DPV) (A) e radiação global e radiação fotossinteticamente ativa (PAR) (B), durante os horários de avaliação das mudas.

FIGURE 3: Average data of temperature (T), air relative humidity (UR) and steam pressure deficit (DPV). (A) and global radiation and photosynthetic active radiation (B), during the cutting evaluation timetable.

\section{Delineamento experimental}

Os dados foram analisados utilizando métodos de amostragem simples ao acaso, com objetivo de verificar o tamanho amostral para uma população infinita de mudas, considerando o nível de significância de 5\% de probabilidade e um desvio (d) de $10 \%$ em torno da média da amostra. Após o dimensionamento da amostra, para a avaliação de condutividade hidráulica foi obtido o intervalo de confiança a $5 \%$ de probabilidade e, para as demais avaliações, o erro padrão da média.

\section{RESULTADOS E DISCUSSÃO}

Na Figura 4 pode-se observar que as mudas crescidas nos tubetes com a indução de deformação (CD) apresentaram o volume do sistema radicular semelhante às mudas cultivadas no recipiente sem deformação do sistema radicular (SD).

Torna-se evidente que o volume radicular não foi influenciado pela indução de deformações radiculares, uma vez que o volume ocupado pelas plaquetas no interior dos tubetes pode ser considerado pequeno, o que não causou alteração no volume ocupado pelas raízes. Caso o volume radicular fosse modificado no tratamento $\mathrm{CD}$, os efeitos relacionados à capacidade fotossintética e às relações hídricas poderiam ser confundidos com a redução no volume do sistema radicular. De fato, diferentes autores (SHI et al., 2008; SHI et al., 2007; NETTO et al., 2006; ZHU et al., 2006; GOTO et al., 2002 e WILL e TESKEY, 1997) têm mostrado que a redução no volume do recipiente de cultivo causa comprometimentos na capacidade fotossintética

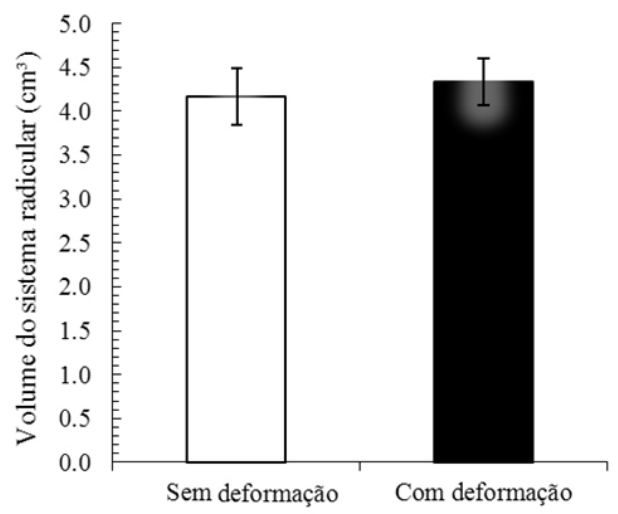

FIGURA 4: Volume do sistema radicular de mudas clonais de eucalipto com (CD) e sem deformação (SD) do sistema radicular. Barras verticais indicam o erro padrão da média $(\mathrm{n}=15)$.

FIGURE 4: Root volume of eucalypt clonal cuttings with (CD) and without (SD) root malformation. Vertical bars point out average standard error $(n=15)$. 
e nas relações hídricas de algumas espécies de plantas. Da mesma forma, à medida que se aumenta o volume dos recipientes e, consequentemente, do substrato, tem-se maior produção de raízes.

Contudo, alguns autores têm relatado que quando uma raiz encontra-se sob condição de impedimento mecânico, o diâmetro desta raiz torna-se maior, ou seja, as raízes tornam-se mais grossas (ATWELL, 1988, MATERECHERA et al., 1991 e GUIMARÃES et al., 2001). Este fato pode mostrar que, nas plantas cultivadas com indução de deformação, as raízes grossas podem ter contribuído para o volume total do sistema radicular, contudo, não avaliado no presente trabalho.

De acordo com os dados apresentados na Figura 5, à medida que se aumenta a pressão em torno do sistema radicular, ocorre um aumento na quantidade de água que sai do caule.

Os resultados mostram que, nas mudas sem deformação, o aumento da pressão resultou em um incremento na saída de água do caule. Esta saída de água esta associada à maior condutividade hidráulica das raízes das plantas cultivadas nos tubetes que não causaram deformação no sistema radicular das mudas. De fato, as plantas sem deformações

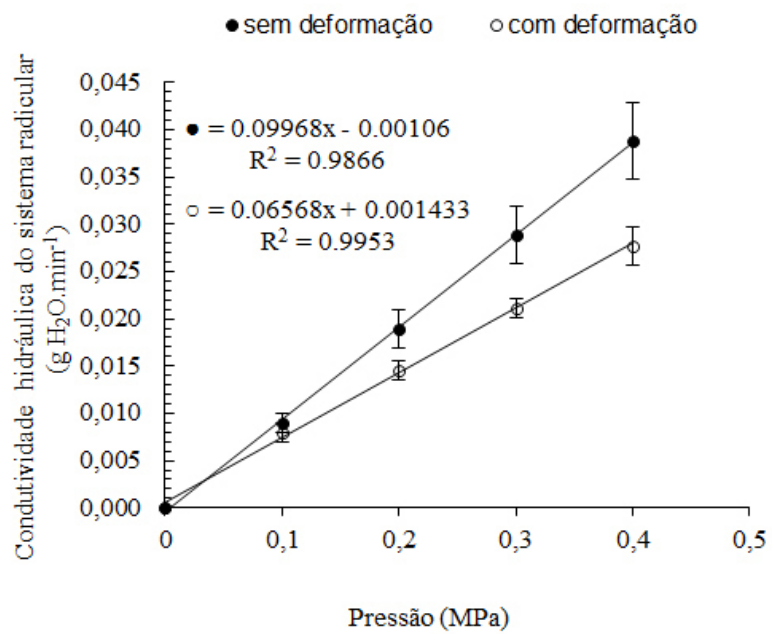

FIGURA 5: Condutividade hidráulica acumulada do sistema radicular de mudas clonais de eucalipto nos dois tratamentos (• Sem deformação, o com deformação). As barras verticais indicam o intervalo de confiança da média $(n=15)$.

FIGURE 5: Accumulated root hydraulic conductivity of eucalypt clonal cuttings in both treatments $(\bullet$ without malformation, 0 with malformation). The vertical bars indicate the confidence interval of the mean $(n=15)$. radiculares apresentaram uma condutividade hidráulica de $0,100 \mathrm{~g} \mathrm{H}_{2} \mathrm{O} \mathrm{MPa}^{-1}$, enquanto que as plantas com deformações apresentaram um valor de $0,066 \mathrm{~g} \mathrm{H}_{2} \mathrm{O} \mathrm{MPa}{ }^{-1}$. Estes valores, que são representados pela inclinação da curva, estão mostrados na Figura 5.

$\mathrm{Na}$ pressão de $0,1 \mathrm{MPa}$ não houve diferenças na condutividade hidráulica entre os dois tratamentos, mas com o aumento da pressão para valores superiores a $0,1 \mathrm{MPa}$ os tratamentos passaram a apresentar diferenças entre si, realçando os efeitos das deformações radiculares na queda da $\mathrm{K}_{\mathrm{L}}$ (Figura 5).

Dentre as funções do sistema radicular está a absorção de água e de nutrientes, função esta essencial ao fluxo de água e nutrição mineral das plantas (TYREE, 2003). De acordo com Huang e Nobel (1994), a condutividade hidráulica da raiz combina os componentes de condutiviade em todo o sistema radicular, da superfície da raiz para o xilema e deste tecido para a planta inteira. Nesse sentido, pode-se afirmar que as mudas com o sistema radicular deformado, quando cultivadas sob condição de campo, poderão ter maiores dificuldades na absorção e aquisição de água e nutrientes minerais.

A Tabela 1 mostra a dispersão dos dados de correlação entre a condutividade hidráulica radicular com o volume de raízes.

Os dados da Tabela 1 refletem as informações das Figuras 4 e 5. De acordo com as figuras, as mudas do tratamento SD apresentaram maior $\mathrm{K}_{\mathrm{L}}$, ainda que o volume de raiz não tenha apresentado diferenças estatísticas em relação às mudas do tratamento CD. Este resultado pode estar relacionado aos efeitos causados pelas deformações impostas ao sistema radicular nas mudas do tratamento $\mathrm{CD}$, pois, de acordo com Tyree e Zimmermann (2002), as características anatômicas do sistema de condução

TABELA 1: Correlação entre a condutividade hidráulica do sistema radicular e o volume de raiz.

TABLE 1: Correlation between root hydraulic conductivity and root volume.

\begin{tabular}{cc}
\hline Pressão & Correlação \\
\hline 0,1 & $-0.0394^{\text {ns }}$ \\
0,2 & $-0.0310^{\text {ns }}$ \\
0,3 & $-0.0538^{\text {ns }}$ \\
0,4 & $-0.1132^{\text {ns }}$ \\
\hline
\end{tabular}


de água das plantas podem apresentar um impacto sobre a sua condutividade hidráulica. Huang e Eissenstat (2000) e Solari et al. (2006), também relatam que a condutividade hidráulica pode ser alterada em função da anatomia da raiz. De acordo com McElrone et al. (2004), a resistência ao fluxo de água no xilema é determinada em parte pelo diâmetro e comprimento dos vasos condutores responsáveis pelo transporte de água. Ainda, segundo o autor, para uma mesma diferença de pressão em um segmento, mesmo um pequeno aumento no diâmetro médio do vaso condutor resulta em efeitos exponenciais na condutividade hidráulica específica. Sendo assim, é plausível que prováveis reduções no diâmetro dos vasos condutores, causados pela ocorrencia da deformação radicular, tenham resultado na redução da condutividade hidráulica do sistema radicular das mudas de eucalipto submetidas à indução de deformação (Figura 5).

A Figura 6 mostra os valores médios do teor de clorofila de mudas clonais de eucalipto em função das técnicas de produção.

Neste experimento, não houve diferença significativa, entre os tratamentos, para o teor de clorofila nas folhas (Figura 6). Este fato mostra que, na condição de viveiro, embora as plantas com indução de deformações radiculares tenham apresentado comprometimentos na condutividade hidráulica do sistema radicular, este

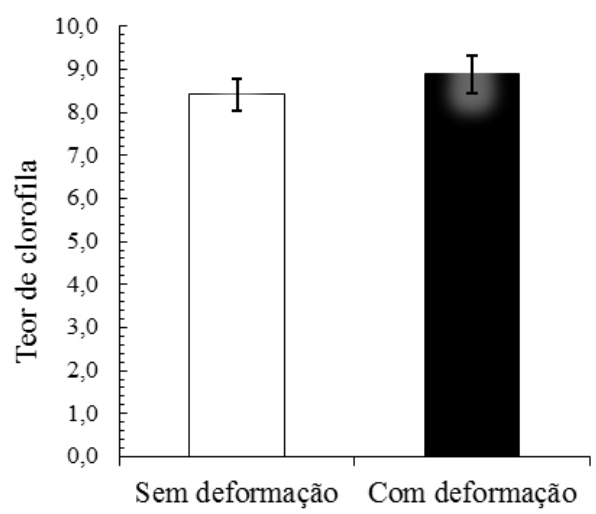

FIGURA 6: Teor de clorofila de mudas clonais de eucalipto nos dois tratamentos (SD - sem deformação e CD - com deformação). As barras verticais indicam o erro padrão da média $(n=6)$.

FIGURE 6: Chlorophyll content of eucalypt clonal cuttings in both treatments (SD - without malformation, CD - with malformation). Vertical bars point out average standard error $(n=6)$. comprometimento não causou alterações nos teores de clorofilas, o que evidencia que este estresse não causou degradação nestes pigmentos fotossintéticos. De acordo com Hendry e Price (1993), o teor de clorofila é influenciado por diversos fatores bióticos e abióticos, e reduzidos valores destes pigmentos fotossintéticos podem mostrar comprometimentos na capacidade fotossintética das plantas (NETTO et al., 2005). Em cafeeiro, Netto et al. (2005), Reis et al. (2006), e Godoy et al. (2008), mostraram que a leitura SPAD teve correlação elevada e positiva com o teor de nitrogênio nas folhas. Os dois últimos autores mostraram que a produtividade das plantas correlacionou-se com os valores do medidor portátil de clorofilas.

As mudas produzidas com a indução de deformações radiculares apresentaram as taxas fotossintéticas mais baixas (Figura 7), ao longo do dia. As respostas da taxa fotossintética em relação ao tempo foram similares às respostas da condutância estomática e da transpiração (Figura 7). A partir do meio dia, o aumento na diferença entre os dois tratamentos SD e CD nos valores variáveis relacionadas às trocas gasosas podem estar relacionadas à maior demanda hídrica do ar no período da tarde (Figura 3). Neste período, o ar mais seco promove uma demanda hídrica intensa sobre a planta. Uma vez que as plantas com indução de deformações radiculares apresentaram menor condutividade hidráulica do sistema radicular e, consequentemente, na absorção de água, proporcionando um retardo no abastecimento de água para a parte aérea das plantas cultivadas na condição de indução de deformações do sistema radicular. Tal fato causou um estresse hídrico moderado, o que promoveu o fechamento estomático, comprometendo assim o processo transpiratório das plantas. De fato, estudos com indução da cavitação do xilema (SPERRY et al., 1993) e poda de raízes (TESKEY et al., 1983; MEINZER e GRANTZ, 1990) têm mostrado a relação positiva entre a condutividade hidráulica e a condutância estomática. Segundo Teskey et al. (1983), Sperry et al. (1993) e Saliendra et al. (1995), a resposta em $\mathrm{g}_{\mathrm{s}}$ ocorre dentro de minutos após a manipulação, e o status hídrico total da folha pode permanecer constante. Esta ligação entre gs e $\mathrm{K}_{\mathrm{L}}$ torna-se elevada, uma vez que, durante o processo fotossintético, o estômato trabalha no sentido de otimizar a assimilação fotossintética do carbono e, em outro sentido, ele trabalha controlando a perda de água pela folha, para evitar comprometimentos 


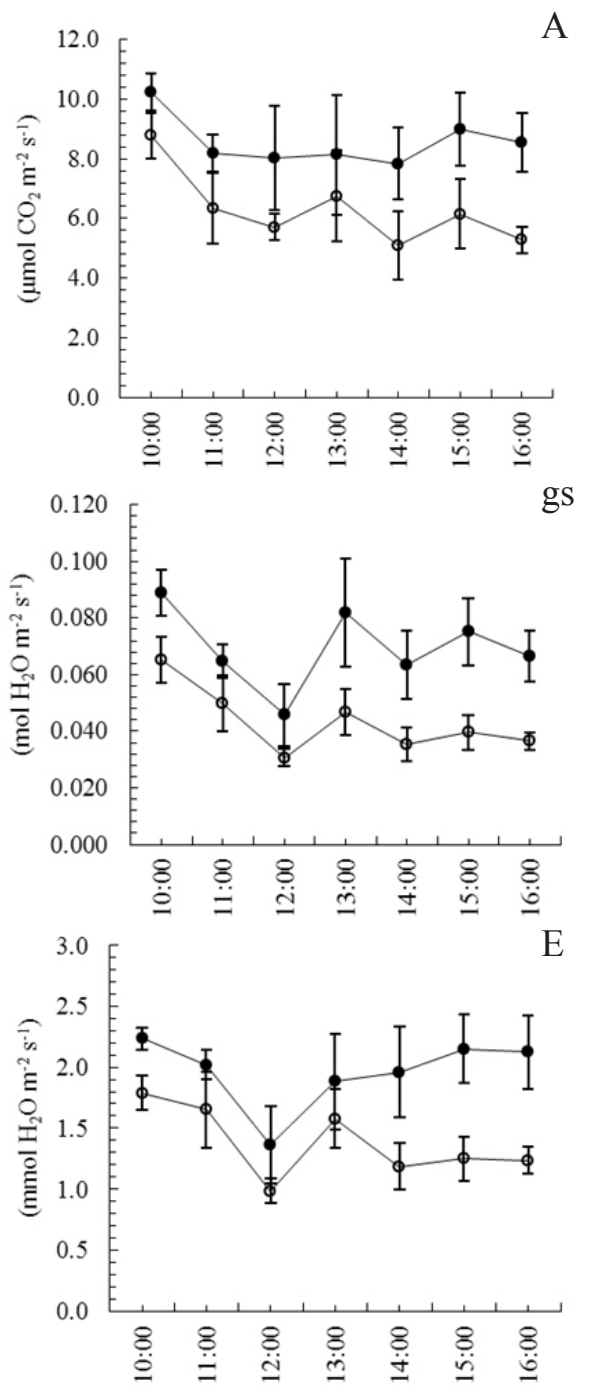

FIGURA 7: Taxa fotossintética (A), condutância estomática (gs) e transpiração (E) de mudas clonais de eucalipto, ao longo do dia, nos dois tratamentos (• sem deformação, ○ com deformação). As barras verticais indicam o erro padrão da média $(n=6)$.

FIGURE 7: Photosyntetic rate (A) stomatic conductance (gs) and transpiration (E) of eucalypt clonal cuttings along the day in both treatments ( $\bullet$ without malformation, $\bigcirc$ with malformation). The vertical bars point out average standard error $(n=6)$.

com a relação hídrica da folha (HUBBARD et al., 2001). Estes danos estão associados ao fenômeno de cavitação e distúrbios nas relações hídricas e no processo bioquímico da célula (HUBBARD et al., 2001). Ainda, estes autores têm mostrado a elevada e positiva relação entre $K_{L}$ e a taxa fotossintética e transpiração.

Neste trabalho com mudas de eucalipto, as plantas do tratamento $\mathrm{CD}$ apresentaram em algum momento do cultivo, um impedimento mecânico proporcionado pelas plaquetas de alumínio. Hartung et al. (1994) têm relatado que, sob condição de impedimento mecânico do sistema radicular, a planta pode aumentar a produção de ácido abscísico (ABA) e segundo Raschke et al. (1987), esse fitohormônio promove o fechamento estomático. Com base nesta informação, pode-se sugerir que, apesar dos efeitos de $K_{L}$ sobre gs, neste experimento, o ABA também pode estar envolvido no fechamento estomático e assim, promover reduções nos valores da taxa fotossintética líquida e da transpiração. Ainda, as plantas com raízes crescendo sob condição de confinamento, o que pode representar um impedimento mecânico, apresentam redução na capacidade fotossintética (GOTO et al., 2002; SHI et al., 2008). Will e Teskey (1997) verificaram, em mudas de pinus, queda na taxa fotossintética líquida à medida que o volume do recipiente foi reduzido de 18,9 para 0,6 litros. Shi et al. (2008), Shi et al. (2007), Netto et al. (2006) e Zhu et al. (2006), os dois primeiros trabalhando com tomate, e os seguintes com café e videira, respectivamente, também verificaram reduções na taxa fotossintética em plantas submetidas ao confinamento do sistema radicular. Entretanto, nestes trabalhos vários efeitos indiretos, que não os efeitos apenas hidráulicos, causaram comprometimentos na assimilação fotossintética do carbono.

A Figura 8 mostra os resultados da eficiência fotoquímica de mudas clonais de eucalipto submetidas a diferentes sistemas de produção.

Os resultados na Figura 8 mostram que, a partir das $12 \mathrm{~h}$, nas plantas com deformação do sistema radicular, os efeitos não estomáticos, associados à atividade do fotossistema II, atuaram na diminuição da assimilação fotossintética do carbono. Embora tenha ocorrido recuperação dos valores de $\mathrm{F}_{\mathrm{v}} / \mathrm{F}_{\mathrm{m}}$ às $15 \mathrm{~h}$, neste horário, a taxa fotossintética líquida das plantas com deformação não se recuperou, evidenciando apenas a ação estomática negativa neste horário. Nos horários de maior intensidade luminosa, entre $11 \mathrm{~h}$ e $13 \mathrm{~h}$, o excesso de energia luminosa promove um estado de estresse fotossintético denominado de fotoinibição (ADIR et al., 2003). Esta fotoinibição pode ser avaliada por meio desta relação $\mathrm{F}_{\mathrm{v}} / \mathrm{F}_{\mathrm{m}}$ (ROSENQVIST e KOOTEN, 2003), a qual se mostra inferior ao valor de 0,75 , quando toda a energia absorvida 


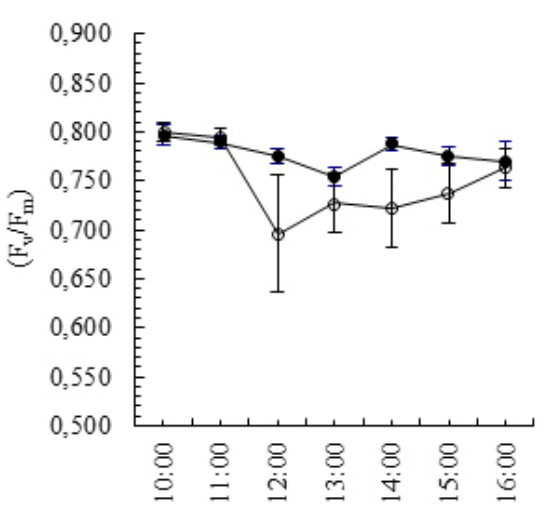

FIGURA 8: Rendimento quântico máximo do PSII $(\mathrm{Fv} / \mathrm{Fm})$ de mudas clonais de eucalipto nos dois tratamentos (• sem deformação, 0 com deformação). Barras verticais indicam o erro padrão da média $(\mathrm{n}=6)$.

FIGURE 8: Maximum quantum yield of PSII (Fv/ Fm) of eucalypt clonal cuttings along the day in both treatments (• without malformation, $\bigcirc$ with malformation). The vertical bars point out average standard error $(n=6)$.

pelos pigmentos fotossintéticos não consegue ser usada pela fotoquímica da fotossíntese, e este excesso de energia luminosa causa destruição dos centros de reação do fotossistema II. Na Figura 8, este fato se mostra evidente nos horários em que as plantas com deformação radicular receberam maior intensidade luminosa (Figura 4). As plantas com indução de deformações radiculares, como estavam com um estresse hídrico moderado (avaliado pela redução em $g_{s}$ e E, Figura 7), mostraram-se mais sensíveis à ação da elevada intensidade luminosa nos horários entre $11 \mathrm{~h}$ e $13 \mathrm{~h}$. De fato, o estresse hídrico potencializa o efeito fotoinibitório sobre o PSII (NAVARI-IZZO e RASCIO, 1999), uma vez que sob condição de limitação do acesso do $\mathrm{CO}_{2}$ aos sítios de carboxilação da rubisco, por meio na redução de $\mathrm{g}_{\mathrm{s}}$, o processo fotoquímico não consegue dissipar o poder redutor, causando assim danos no PSII (redução em $\mathrm{F}_{\mathrm{v}} / \mathrm{F}_{\mathrm{m}}$ ).

Em condição de confinamento do sistema radicular, efeitos não estomáticos sobre o processo fotossintético têm sido relatados em alguns trabalhos (TSCHAPLINSKI e BLAKE, 1985, NETTO et al., 2005).

Os resultados obtidos neste trabalho indicam que em plantas de eucalipto, as deformações físicas causadas pelo recipiente de cultivo podem comprometer as relações hídricas, por meio de reduções na condutividade hidráulica, na condutância estomática e na transpiração, com efeitos sobre a capacidade fotossintética da planta. Sendo assim, torna-se necessária a busca de novas tecnologias para a produção de mudas, especificamente recipientes que favoreçam uma melhor arquitetura do sistema radicular, que dificulte, ou mesmo impeça a restrição mecânica da raiz, evitando limitações hídricas, por meio de deformações radiculares, e proporcionando um estabelecimento, e crescimento mais vigoroso no campo.

\section{CONCLUSÕES}

A indução de deformações radiculares não resultou em queda no volume de raiz de mudas clonais de eucalipto. Contudo, a indução de deformações radiculares foi responsável pela redução na condutividade hidráulica do sistema radicular e na taxa fotossintética de mudas clonais de eucalipto, sendo esta última afetada por fatores estomáticos e não estomáticos associados à eficiência quântica máxima do fotossistema II.

\section{AGRADECIMENTOS}

À FIBRIA CELULOSE S.A. pela cessão de sua estrutura física de laboratório e viveiro e, também, pelo apoio técnico-cientifico e logístico.

\section{REFERÊNCIAS BIBLIOGRÁFICAS}

ADIR, N. et al. Photoinhibition - a historical perspective. Photosynthesis Research, Netherlands, n. 76, 343-370, 2003.

ATWELL, B. J. Physiological responses of lupin roots to soil compaction. Plant and Soil, Crawley, n.111, p. 277-281, 1988.

BARROSO, D. G. et al. Efeitos do recipiente sobre o desempenho pós-plantio de Eucalyptus camaldulensis e E. urophylla. Revista Árvore, Viçosa-MG, v. 24, n. 3, p. 291-296, 2000.

BENGOUGH, A. G. et al. Root responses to soil physical conditions; growth dynamics from field to cell. Journal of Experimental Botany, Oxford, v. 57, n. 2, p. 437-447, 2006.

BOLHÀR-NORDENKAMPF, H. R. et al. Chlorophyll fluorescence as a probe of the photosynthetic competence of leaves in the field: a review of current instrumentation. Functional 
Ecology, London, n. 3, p. 497-514, 1989.

CARMI, A.; HEUER, B. The Role of Roots in the Control of Bean Shoot Growth. Annals of Botany, Leicester, n. 48, p. 519-527, 1981.

FREITAS, T. A. S. Sistemas de blocos prensados para produção de mudas clonais de eucalipto. 2003, 115 f. Dissertação (Mestrado em Produção Vegetal) - Universidade Estadual do Norte Fluminense Darcy Ribeiro - Campos dos Goytacazes - RJ, 2003.

FREITAS, T. A. S. et al. Desempenho radicular de mudas de eucalipto produzidas em diferentes recipientes e substratos. Revista Árvore, ViçosaMG, v. 29, n. 6, p. $853-861,2005$.

GODOY, L. J. G. et al. Índice relativo de clorofila e o estado nutricional em nitrogênio durante o ciclo do cafeeiro fertirrigado. Revista Brasileira de Ciência do Solo, Viçosa-MG, n. 32, p. 217-226, 2008.

GOTO, T. et al. Photosynthetic, evapotranspiratory and leafmorphological properties of chrysanthemum grown under root restriction as affected by fertigation frequency. Japanese Society for Horticultural Science, Tokyo, n.71, p. 277-283, 2002.

GUIMARAES, C. M.; MOREIRA, J. A. A. Compactação do solo na cultura do arroz de terras altas. Pesquisa Agropecuaria Brasileira, Brasília, v. 36, n. 4, 2001.

HAMEED, M. A.; REID, J. B.; ROWE R. N. Root confinement and its effects on the water relations, growth and assimilate partitioning of tomato (Lycopersicun esculentum Mill). Annals of Botany, Bristol, v. 59, n. 6, 685-692, 1987.

HARTUNG, W.; ZHANG, J.; DAVIES, W. J. Does abscisic acid play a stress physiological role in maize plants growing in heavily compacted soil? Journal Experimental Botany, Oxford, v. 45, n. 2, p. 221-226, 1994.

HENDRY, G. A. F.; PRICE, A. H. Stress indicators: chlorophylls and carotenoids. In: Hendry, G. A. F. and Grime J.P. (Eds.) London: Chapman \& Hall, 148-152p. 1993.

HUANG, B.; EISSENSTAT, D. M. Linking hydraulic conductivity to anatomy in plants that vary in specific root length. American Society for Horticultural Science, Stanford, n. 125, p. 260-264, 2000.

HUANG, B.; NOBEL, P. S. Root hydraulic conductivity and its components, with emphasis on desert succulents. Agronomy Journal, Madison, n. 86, p. 767-774, 1994.

HUBBARD, R. M. et al. Stomatal conductance and photosynthesis vary linearly with plant hydraulic conductance in ponderosa pine. Plant, Cell $\&$ Environment, Logan, v. 24, n. 1, p. 113-121, 2001. HURLEY, M. B.; ROWART, J. S. Resistance to root growth and changes in the concentrations of ABA within the root and xylem sap during root-restriction stress. Journal of Experimental Botany, Oxford, v. 50, n. 335, p. 799-804 1999.

JACKSON R. B.; SPERRY, J. S.; DAWSON, T. E. Root water uptake and transport: using physiological processes in global predictions. Trends in Plant Science, Cambridge, n. 5, p. 482-488, 2000.

MATERECHERA, S. A.; DEXTER, A. R.; ALTSON, A. M. Penetration of very strong soils buy seedlings roots of different plant species. Plant and Soil, Crawley, v. 135, p. 31-41, 1991.

MCELRONE, A. J. et al. Variation in xylem structure and function in stems and roots of trees to $20 \mathrm{~m}$ depth. New Phytologist, Sheffield, n. 163, p. 507-517, 2004.

MEINZER, F. C.; GRANTZ, D. A. Stomatal and hydraulic conductance in growing sugarecane: stomatal adjustment to water transport capacity. Plant, Cell and Environment, Logan, v. 13, n. 4, p. 383-388, 1990.

NAVARI-IZZO, F.; RASCIO, N. Plant response to water-deficit conditions. In: Pessarakli, M. ed. Handbook of plant and crop stress, New York: Marcel Dekker Inc, 1999. p. 231-270.

NETTO, A. T.; CAMPOSTRINI, E.; GOMES, M. M.A. Efeitos do confinamento radicular nas medidas biométricas e assimilação de $\mathrm{CO}_{2}$ em plantas de Coffea canephora Pierre. Revista Brasileira de Agrociência, Pelotas, v. 12, n. 3, p. 295-303, 2006. NETTO A. T. et al. Photosynthetic pigments, nitrogen, chlorophyll a fluorescence and SPAD-502 readings in Coffea leaves. Scientia Horticulturae, Netherlands, n. 104, p. 199-209, 2005.

NIKOLOVA, P. S. et al. Combined application of computer tomography and light microscopy for analysis of conductive xylem area in coarse roots of European beech and Norway spruce. European Journal of Forest Research, Freising, n. 128, p. 145-153, 2009.

NOVAES, A. B. et al. Comportamento de mudas de Pinus taeda produzidas em raiz nua e em dois tipos de recipientes, 24 meses após o plantio. Floresta, Curitiba, n. 31, p. 62-71, 2002.

OSMONT, K. S.; SIBOUT, R.; HARDTKE, C. S. Hidden Branches: Developments in Root System Architecture. The Annual Review of Plant Biology, California, n. 58, p. 93-113, 2007. 
PETERSON, T. A.; REINSEL, M. D.; KRIZEK, D. T. Tomato (Lycopersicon esculentum Mill., cv. 'Better Bush') Plant Response to Root Restriction. I. Alteration of Plant Morphology. Journal of Experimental Botany, Oxford, v. 42, n. 243, p. 1233-1240, 1991.

RASCHKE, K. Action of abscisic acid on guard cells. In: ZEIGER, E.; FARQUHAR, G. D.; COWAN, I. R., eds, Stomatal Function, Stanford: Stanford University Press, 1987. p 253-279.

REIS, A. R. et al. Diagnóstico da exigência do cafeeiro em nitrogênio pela utilização do medidor portátil de clorofila. Bragantia, Campinas, v. $65, \mathrm{n}$. 1, p. 163-171, 2006.

REIS, G. G. et al. Efeito da poda de raízes sobre a arquitetura do sistema radicular e o crescimento de mudas de Eucalyptus grandis e Eucalyptus citriodora produzidas em tubetes. Revista Árvore, Viçosa-MG, v. 15, n. 1, p. 43 - 54, 1991.

ROSENQVIST, E.; KOOTEN, O. V. Chlorophyll fluorescence: a geral description and nomenclature. In: DeELL, J. R.; TOIVONEN, P. M. A. Practical applications of chlorophyll fluorescence in plant biology, Dordrecht, Kluwer academic publishers, 2003. 259 p.

ROSSIELLO, R. O. P. et al. Comparação dos métodos fotoelétrico e da interseção na determinação da área, comprimento e raio médio radicular. Pesquisa Agropecuária Brasileira, Brasília, v. 30, n. 5, p. 633-638, 1995.

RUFF, M. S. et al. Restricted Root Zone Volume: Influence on Growth and Development of Tomato. American Society for Horticultural Science, Stanford, v. 112, n. 5, p. 763-769, 1987.

SALIENDRA, N. Z.; SPERRY, J. S.; COMSTOCK, J. P. Influence of leaf water status on stomatal response to humidity, hydraulic conductance, and soil drought in Betula occidentalis. Planta, Bonn, n. 196, p. 357-366, 1995.

$\mathrm{SHI}, \mathrm{K}$. et al. Low $\mathrm{O}_{2}$ supply is involved in the poor growth in root-restricted plants of tomato (Lycopersicon esculentum Mill.). Environmental and Experimental Botany, Paris, n. 61, p. 181-
189, 2007.

SHI, K. et al. Root restriction-induced limitation to photosynthesis in tomato (Lycopersicon esculentum Mill.) leaves. Scientia Horticulturae, Netherlands, n. 117, p. 197-202, 2008.

SOLARI. L. I.; PERNICE, F.; DEJONG, T. M. The relationship of hydraulic conductance to root system characteristics of peach (Prunus persica) rootstocks. Physiologia Plantarum, Helsinki, n. 128, p. 324-333, 2006.

SPERRY, J. S.; POCKMAN, W. T. Limitation of transpiration by hydraulic conductance and xylem cavitation in Betula occidentalis. Plant, Cell and Environment, Logan, n. 16, p. 279-287, 1993.

TERNESI, $M$. et al. Root-shoot signalling in sunflower plants with confined root systems. Plant and Soil, Crawley, n. 166, p. 31-36, 1994.

TESKEY, R. O.; HINCKLEY, T. M.; GRIER, C. C. Effect of interruption of flow path on stomatal conductance of Abies amabilis. Journal of experimental botany, Oxford, n. 34, p. 1251 1259, 1983

TSCHAPLINSKI, T.J.; BLAKE, T.J. Effects of root restriction on growth correlations, water relations and senescence of alder seedlings. Physiologia Plantarum, Lund, v. 64, n. 2, p. 167-176, 1985.

TYREE, M. T. Hydraulic limits on tree performance: transpiration, carbon gain and growth of trees. Trees, Vancouver, n. 17, p. 95-100, 2003. TYREE, M. T.; ZIMMERMANN, M.H. Xylem Structure and the Ascent of Sap, Berlin: Springer Verlag, 2002.

WILL, R. E.; TESKEY, R. O. Effect of elevated carbon dioxide concentration and root restriction on net photosynthesis, water relations and foliar carbohydrate status of loblolly pine seedlings. Tree Physiology, Durham. n. 17, p. 655-661, 1997.

ZHU, L. et al. Vine growth and nitrogen metabolism of 'Fujiminori' grapevines in response to root restriction. Scientia Horticulturae, Netherlands, v. 107, n. 143-149, 2006. 